\title{
Arsenic characteristics in the terrestrial environment in the vicinity of the Shimen realgar mine, China
}

\author{
C.Y. Wei \\ Key Laboratory of Land Surface Pattern and Simulation, Institute of Geographic Sciences and Natural Resources \\ Research, Chinese Academy of Sciences, Beijing, P.R. China
}

\begin{abstract}
In this study, multiple types of samples, including soils, plants, litter and soil invertebrates, were collected from a former arsenic (As) mine in China. The total As concentrations in the soils, earthworms, litter and the aboveground portions of grass from the contaminated area followed the decreasing order of $83-2224 \mathrm{mg} \mathrm{kg}^{-1}$, $31-430 \mathrm{mg} \mathrm{kg}^{-1}, 1-62 \mathrm{mg} \mathrm{kg}^{-1}$ and $2-23 \mathrm{mg} \mathrm{kg}^{-1}$, respectively. XANES analysis revealed that the predominant form of As in the soils was arsenate $(\mathrm{As}(\mathrm{V}))$. In the grass and litter of the native plant community, inorganic As species were the main species, while minor amounts of DMA, MMA were also detected by HPLC-ICP-MS. The major As species extracted from earthworms were inorganic and AsB was the only organic species present in the earthworm samples, although at low proportions. The internal bioconversion of other As species is hypothesized to contribute greatly to the formation and accumulation of AsB in earthworms, although the direct external absorption of organic As from soils might be another source. This study sheds light on the potential sources of complex organoarsenicals, such as AsB, in terrestrial organisms.
\end{abstract}

\section{INTRODUCTION}

Arsenic (As) is a toxic metalloid element that is widely distributed in the environment $(\mathrm{Ng}, 2005)$. The As toxicity is known to depend on the chemical species $(\mathrm{Ng}$, 2005). In general, inorganic As species are more toxic than organic forms. Therefore, it is essential to monitor both the total As concentration and As speciation in environmental and biological samples. Generally, As can enter plants through their root systems and can be dispersed by leaf litter, posing a threat to soil invertebrates living in As-contaminated soils (Wang et al., 2016). To the best of our knowledge, the literature has primarily focused on the relationships between soils and plants or earthworms in terrestrial ecosystems, but such a limited scope is insufficient (Kramar et al., 2017). To further understand the As cycling in the terrestrial environment, comprehensive studies on As bioaccumulation and biotransformation via a soilplant-leaf litter-terrestrial fauna approach are highly desired.

\section{METHODS AND MATERIALS}

\subsection{Sampling}

The Shimen realgar mine $\left(29^{\circ} 38^{\prime} 11^{\prime \prime}-29^{\circ} 38^{\prime} 43^{\prime \prime} \mathrm{N}\right.$, $111^{\circ} 2^{\prime} 06^{\prime \prime}-111^{\circ} 2^{\prime} 23^{\prime \prime} \mathrm{E}$ ) is located in Shimen County, Hunan Province, China. This mine contains the largest reserves of realgar in Asia. In this study, eleven sites in the contaminated area (around the smelter and tailings dam), while six sites in the uncontaminated area
( $>4 \mathrm{~km}$ from the upper part of the smelter) were established at different distances from the center of the mine.

\subsection{Total arsenic analysis}

Approximately $0.05 \mathrm{~g}$ of each soil sample was digested with $10 \mathrm{ml}$ of $5: 1 \mathrm{HNO}_{3}: \mathrm{HClO}_{4}$, and approximately $0.2 \mathrm{~g}$ of each biological sample was digested with $10 \mathrm{ml}$ of $9: 1 \mathrm{HNO}_{3}: \mathrm{HClO}_{4}$ in acid-cleaned vessels. The test tubes were left overnight and then heated at $140^{\circ} \mathrm{C}$ on an electric hot plate. The samples were analyzed using an AFS-8230 spectrometer (Beijing Titian Co., China).

\subsection{Arsenic speciation analysis}

Arsenic speciation was analyzed in aqueous methanol extracts of the dried samples and of the reference materials as described in the literature (Ciardullo et al., 2010) with some modifications. The K-edge XANES spectra of As were obtained at the 1W1B beam line at the Beijing Synchrotron Radiation Facility (BSRF), Beijing, China.

\section{RESULTS AND DISCUSSION}

\subsection{Arsenic characterization in soils}

In contaminated areas, the soil $\mathrm{pH}$ varied markedly from 4.51 to 7.98 , while the content of TOM ranged from 18.05 to $49.33 \mathrm{~g} \mathrm{~kg}^{-1}$. In the uncontaminated areas, little variation in soil $\mathrm{pH}(6.21-6.74)$ was found, 
and the TOM content varied from 16 to $26 \mathrm{~g} \mathrm{~kg}^{-1}$. The As concentrations in soils collected from uncontaminated areas were in the range of $8-23 \mathrm{mg} \mathrm{kg}^{-1}$, which were much lower than those in contaminated areas (61-2224 $\mathrm{mg} \mathrm{kg}^{-1}$ ).

\subsection{Arsenic concentration in the native plants}

In general, the As concentrations in this study displayed a pattern of leaves $>$ stems, similar to the results of other studies (Tsipoura et al., 2017). The As uptake by plants was found to differ among species; the BF in terrestrial plants, excluding two Pteris species, varied from 0.0003 to 0.20 , which was in the same range as that reported in the literature. The fern species Pteris vittata and Pteris cretica collected from contaminated sites showed the greatest As concentrations among the sampled plants, with up to $584 \mathrm{mg} \mathrm{kg}^{-1}$ and $391 \mathrm{mg} \mathrm{kg}^{-1}$ As in their aboveground parts, respectively. In this study, the As concentrations in corn much higher than those from the uncontaminated area. Similarly, the indigenous Miscanthus sinensis and Conyza Canadensis. Therefore, the past As mining and smelting activities appear to still be causing As accumulation in crops and indigenous plants.

\subsection{Arsenic concentration in the soil-grass-litter-invertebrate system}

In general, the As level increased in earthworms with increasing As concentration in their surroundings in this study, which is in agreement with previous studies. BFs tended to decrease with increasing As concentrations in soils, suggesting that As is mainly autoregulated and can be sequestered by earthworms. Earthworms accumulated more As than did the grass and litter in this study. Significant positive correlations were found between the As concentrations in the soils and earthworms, the earthworms and leaf litter, and the soils and leaf litter, suggesting close relationships among the As inputs in the soil-litter-earthworm system.

\subsection{Arsenic transformation in the terrestrial environment}

In the present study, $\mathrm{As}(\mathrm{V})$ was the most dominant form in the soils, as determined by XANES analysis, while As(III) was the predominant As species present in many terrestrial plant species in this study. Therefore, the As $(\mathrm{V})$ taken up by the plants was converted to As(III). Notably, various organic As in plant suggested organoarsenic species taken up from soils. The main As species extracted from earthworms was inorganic As. AsB was the only organoarsenic compound detected in earthworms. In this study, no or trace amounts of AsB were detected, while other organic As species, such as AsC, DMA, and MMA, and an unknown As species appeared at relatively high percentages in plants or leaf litter. Therefore, the AsB in earthworms does not largely come from ambient environmental sources, but a result of the biotransformation by earthworms themselves (Langdon et al., 2003; Button et al., 2009).

\section{CONCLUSIONS}

In this study, the total As concentration and As speciation were studied in different environmental media from both contaminated and uncontaminated area. The aboveground parts of the local plant community in this mining area contained low As concentrations. With increasing As concentration in the environment, the concentration of As in earthworms generally increased, while the BFs decreased in the present study. The most abundant As compounds found in plants, leaf litter and grass were inorganic As species, while a variety of organoarsenic species were also detected. The high proportion of inorganic As in earthworms suggested dietary sources, while the appearance of AsB as the only organoarsenic species was largely the result of biotransformation from other As species.

\section{ACKNOWLEDGEMENTS}

This study was financially supported by the National Natural Science Foundation of China (Grant No. 41571470).

\section{REFERENCES}

Button, M., Jenkin, G.R.T., Harrington, C.F. \& Watts, M.J. 2009. Arsenic biotransformation in earthworms from contaminated soils. J. Environ. Monitor. 11: 1484-1191.

Ciardullo, S., Aureli, F., Raggi, A. \& Cubadda, F. 2010. Arsenic speciation in freshwater fish: Focus on extraction and mass balance. Talanta 81: 213-221.

Kramar, U., Norra, S., Berner, Z., Kiczka, M. \& Chandrasekharam, D. 2017. On the distribution and speciation of arsenic in the soil-plant-system of a rice field in WestBengal, India: A $\mu$-synchrotron techniques based case study. Appl. Geochem. 77: 4-14.

Langdon, C.J., Piearce, T.G., Meharg, A.A. \& Semple, K.T. 2003. Interactions between earthworms and arsenic in the soil environment: A review. Environ. Pollut. 124: 361-373.

$\mathrm{Ng}$, J.C. 2005. Environmental contamination of arsenic and its toxicological impact on humans. Environ. Chem. 2: 146-160.

Tsipoura, N., Burger, J., Niles, L., Dey, A., Gochfeld, M., Peck, M. \& Mizrahi, D. 2017. Metal levels in shorebird feathers and blood during migration through Delaware Bay. Arch. Environ. Con. Toxicol. 72: 562-574.

Wang, Z.F., Cui, Z.J., Liu, L., Ma, Q.C. \& Xu, X.M. 2016. Toxicological and biochemical responses of the earthworm Eisenia fetida exposed to contaminated soil: Effects of arsenic species. Chemosphere 154: 161-170. 